\title{
Naturgartentipp - warum der Woll-Ziest nicht fehlen sollte
}

\author{
Hilke Steinecke
}

\section{Abstract}

Woolly betony (Stachys byzantina) is a robust garden plant for sunny and dry places. The perennial is an important species for the european wool carder bee (Anthidium manicatum), which needs wooly hairs of plants to build nests. The biology of Anthidium manicatum and its relation to Stachys byzantina are briefly presented.

\section{Zusammenfassung}

Woll-Ziest (Stachys byzantina) ist eine robuste Gartenpflanze für sonnig-trockene Standorte. Die Staude ist eine wichtige Art für die Garten-Wollbiene (Anthidium manicatum), die wollige Pflanzenhaare für den Nestbau benötigt. Biologie der Garten-Wollbiene und ihr Bezug zum Woll-Ziest werden kurz vorgestellt.

\section{Attraktive Gartenpflanze}

Der Woll-Ziest (Stachys byzantina) ist ein Lippenblütler, der aus Vorderasien und dem Kaukasus stammt. Bei uns ist er eine beliebte winterharte bodendeckende Zierstaude, die sich für trockene, warme und sonnige Standorte eignet. Blätter sowie Blütenstandsachse sind in Anpassung an seine trockenen Wuchsorte weiß- bis graußfilzig behaart. Die wollig-weichen Blätter erinnern an die Ohren eines Esels, daher auch die Bezeichnung Eselsohr. Seine purpurviolett gefärbten relativ klei-

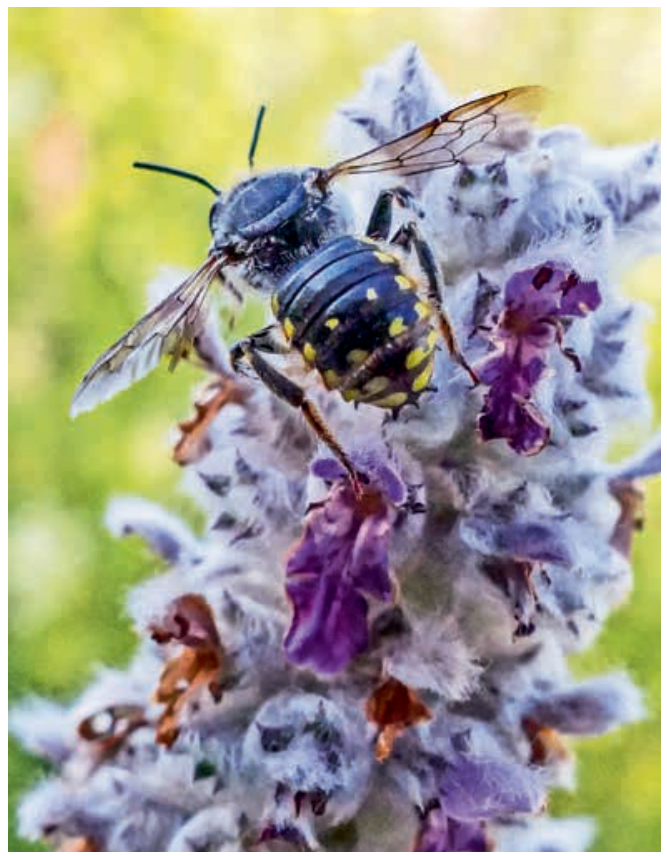

Abb. 1: Männchen der Garten-Wollbiene mit bedorntem Hinterleib an Woll-Ziest. (Foto: H. Steinecke) nen Lippenblüten erscheinen in Scheinquirlen an der Blütenstandsachse.

\section{Pflanzenhaare für den Nestbau}

Für manche Insekten sind wollig behaarte Pflanzen lebensnotwendig, da diese mit den Pflanzenhaaren ihre Nester auskleiden. Neben Woll-Ziest und auch Deutschem Ziest (Stachys germanica) gibt es noch weitere wollig behaarte Arten wie Wolliger Fingerhut (Digitalis lanata) und Kron-Lichtnelke (Lychnis coronaria). Der Woll-Ziest ist aber genüg-

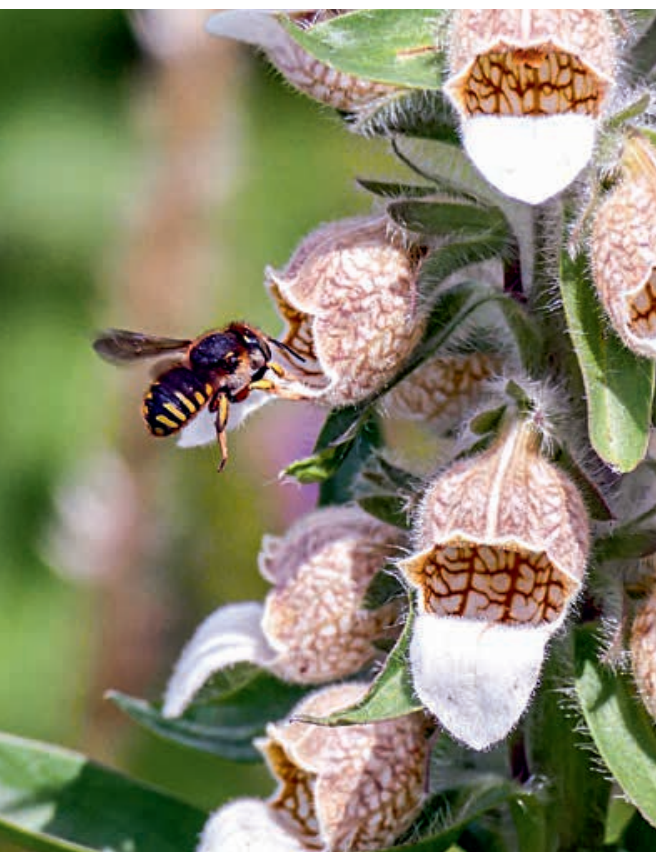

Abb. 2: Weibchen der Garten-Wollbiene mit glattem Hinterleib am Wolligen Fingerhut. (Foto: H. Steinecke) 
sam, ungiftig und wächst gut. Der Wollige Fingerhut (Digitalis lanata) dagegen ist stark giftig und sollte nicht unbedingt in Gärten gepflanzt werden, in denen auch Kinder unterwegs sind.

Eine in unseren Gärten noch häufig anzutreffende Wildbiene, die Pflanzenwolle benötigt, ist die Garten-Wollbiene (Anthidium manicatum). Diese Biene erinnert mit ihrem auffällig schwarzgelb gestreiften Hinterleib an eine Wespe, wobei sie eine gedrungenere Körperform hat und die auffällige Wespentaille fehlt. Die Garten-Wollbiene fliegt relativ hektisch von Blüte zu Blüte, manchmal bleibt sie im Schwebflug in der Luft stehen, ein anderes Mal stürzt sie sich blitzschnell auf eine Blüte, auf der sie nur kurz verweilt. Neben dem Woll-Ziest sind auch Salbei-Arten, Hauhechel (Ononis spinosa) oder Bunte Kronwicke (Coronilla varia) wichtige Nektarpflanzen.

\section{Wehrhafte Männchen}

Die Männchen umfliegen in ihrem Revier beliebte Nektarpflanzen auch auf der Suche nach Weibchen, die hier gerade Nektar trinken. Sie begatten die Weibchen direkt auf der Blüte. Konkurrenten werden aus dem Revier hartnäckig vertrieben. Deshalb sind die Männchen auf ihrem Hinterleib mit fünf spitzen Dornen ausgestattet. Fremde Arten, aber auch andere Wollbienen, werden mit den Dornen attackiert, um sie aus dem Revier zu vertreiben. Einige werden dabei so stark verletzt, dass sie flugunfähig werden und sterben. Nach eigenen Beobachtungen schrecken die bis $18 \mathrm{~mm}$ großen Wollbienen-Männchen noch nicht einmal vor Angriffen auf die mit bis 28 mm Länge deutlich größeren Holzbienen (Xylopia violacea) zurück. Die Weibchen sind unbewehrt und mit 12 mm Körperlänge auch etwas kleiner.

\section{Familienleben der Wollbiene}

Die Paarung kann immer mal wieder auf den Blütenständen des Woll-Ziest beobachtet werden. Diese wird in Windeseile in weniger als einer halben Minute vollzogen. Um den Nestbau kümmert sich danach nur das Weibchen. Bruthöhlen werden in Bodenlöchern oder Hohlräumen von Mauern und Holzbalken angelegt. Das Weibchen schabt von behaarten Pflanzen, sehr gern eben vom Woll-Ziest, die Haare ab und trägt diese mit den

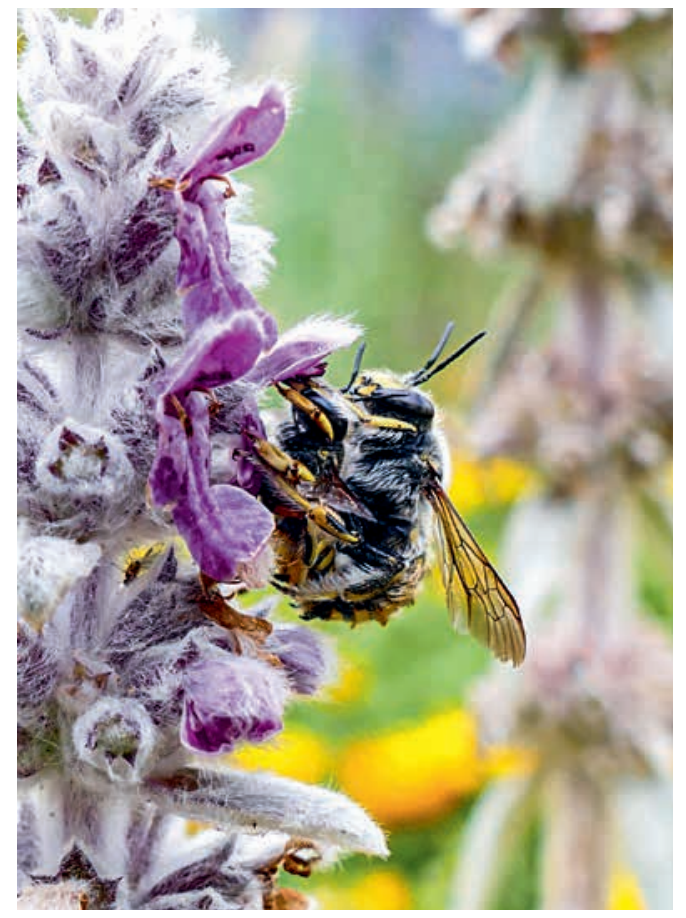

Abb. 3: Paarung auf einem Blütenstand des Wolligen Ziest. Hier werden gleich zwei Geschlechtsvorgänge im Doppelpack vollzogen: Bestäubung der Ziest-Blüte und Begattung des Weibchens. (Foto: H. STEInEcke)

Beinen in die Bruthöhle, um sie damit auszukleiden. Wenn der Nahrungsvorrat eingebracht und die Eier abgelegt sind, wird das Nest mit kleinen Steinchen oder Pflanzenteilen verschlossen. Die nächste Generation der Wollbiene schlüpft erst im folgenden Jahr. Da Wollbienen es warm mögen, sind sie meist erst ab dem Hochsommer unterwegs. Im Palmengarten sind sie regelmäßig in der Steppenwiese zu beobachten, wo auch der Woll-Ziest wächst. Außerdem fliegen sie im Herbst sehr oft die Dornige Hauhechel an.

\section{Internetseiten}

https://mecklenburg-vorpommern.nabu.de/tiere-und-pflanzen/insekten-und-spinnen/bienen-und-co/16979.html

https://naturspaziergang.de/Wildbienen/Megachilinae/Anthidium_manicatum.html

\section{Anschrift der Autorin}

Dr. Hilke Steinecke, Palmengarten Frankfurt,

Siesmayerstr. 61, 60323 Frankfurt;

https://orcid.org/0000-0002-4618-4867 